\title{
Research on Multichannel Supply Chain Pricing Under Different Dominance
}

\author{
Bicheng Yue* \\ School of Management, Bohai University, Jinzhou 121013, Liaoning Province, China \\ *Corresponding author: Bicheng Yue, ybc3000@163.com
}

\begin{abstract}
In a multichannel supply chain comprising of dual-channel retailers with both physical and online channels as well as single-channel e-tailers with online channels, a multichannel demand model for e-commerce is constructed based on customer channel preferences, and a Stackerberg game model with price competition dominated by dual-channel retailers and single-channel e-tailers as well as a Bertrand game model with equal rights are established to analyze the impact of different channel rights structures on the price, demand, and profit of the two retailers. The results show that the single-channel e-tailer under the dual-channel retailer-dominated game has the highest profit, and the dual-channel retailer under the single-channel e-tailer-dominated game has the highest profit; thus, both retailers should accept the other's dominant channel rights for profit maximization.
\end{abstract}

Keywords: Multichannel supply chain; Customer channel preference; Channel power structure; Price competition

Publication date: October 2021; Online publication: October 29, 2021

\section{Introduction}

With electronic information technology and the popularity of smartphones, the development of e-commerce has entered a high-speed era. According to data monitored by the China Electronic Commerce Research Center, China's online retail sales exceeded 12 trillion yuan in 2020, with an increase of $25 \%$. The huge market potential of the online channel has led to the rapid development of single-channel online retailers, such as Amazon, Jingdong, Dangdang, etc. Meanwhile, large retail groups, represented by Suning and Walmart, have established electronic online channels (dual-channel retailers) while maintaining retail sales in physical stores. In order to gain more market demand, dual-channel retailers and single-channel online retailers often engage in price competition. For example, after Jingdong launched the "6-18" campaign, mainstream e-commerce companies, such as Tmall, Suning Tesco, Amazon China, Gome Online, and Dangdang.com, participated in the mid-year promotion. The intensity is comparable to "Double 11." The multi-channelization of product sales certainly improves the flexibility of supply chain on the one hand but intensifies the conflict between channels on the other hand ${ }^{[1,2]}$. This conflict is more obvious when dualchannel retailers and single-channel e-tailers have online sales channels at the same time, in which price is one of the main reasons for the competition between channels. Therefore, pricing strategies in multichannel supply chains deserve attention and research in order to mitigate the conflict between channels as well as to coordinate the profits among supply chain members.

Currently, there are many research on pricing strategies under dual-channel supply chains ${ }^{[3,4]}$, consisting of manufacturers opening online channels and retailers with physical channels. However, there are only a few research on pricing under multichannel supply chains. There are basically two types of research approaches on pricing strategies to reduce or avoid channel conflicts: first, the manufacturer is assumed to be dominant and has the priority of price decisions ${ }^{[5,6]}$; second, the existence of a strong retailer 
is set and dominated by the retailer. In this study, the main difference from previous literatures is that a multichannel supply chain structure is constructed from the perspective of master-slave and equilibrium relationships between dual-channel retailers and single-channel e-tailers in both vertical and horizontal dimensions and a Stackerberg master-slave countermeasure game model with dual-channel retailers and single-channel e-tailers as decision makers is studied from the perspective of customer channel preferences. In addition, the Bertrand game model with dual-channel retailers and single-channel e-tailers as decision makers is also hypothesized. The effects of customer preference for single-channel e-tailers and for dualchannel e-tailers on optimal price, demand, and profit of both retailers are investigated under different channel power structures.

\section{Problem description and model assumptions}

This study explores a supply chain consisting of a single manufacturer, a dual-channel retailer, and a singlechannel e-tailer, where the upstream manufacturer produces a product with unit product $C$ and supplies the product to two downstream retailers at a wholesale price, $W$. The dual-channel retailer sells to consumers via two different distribution channels. The dual-channel retailer's physical channel price is $P_{r}$, the dualchannel retailer's online channel price is $P_{e}$, and the single-channel e-tailer opens an online sales channel with an online channel price of $P_{d}$. In this study, the total demand in the whole market is assumed to be $Q$. Considering that there are three distribution channels in the supply chain, this study assumes that the customer channel preference coefficient of a single-channel e-tailer is $\alpha(0<\alpha<1)$, the customer channel preference coefficient of a dual-channel retailer network channel is $\beta(0<\beta<1)$, and $1-\alpha-\beta$ is the customer channel preference coefficient of a dual-channel retailer physical channel.

In addition, the following assumptions were made: (1) only one product is sold in this multi-channel sales channel; (2) the manufacturer's cost of production, the manufacturer's cost of selling the product, and the retailer's cost of selling the product are all assumed to be zero for ease of analysis; (3) the price elasticity of demand coefficients are equal between channels, and the demand for goods is set to be more influenced by the price of its own channel than by the price of the competing channel, assuming $1>2 k$, i.e. $0<k<0.5$; (4) the manufacturer in this study does not participate in the game decision, and the wholesale price $W$ issued by the manufacturer and the potential total market demand $Q$ are exogenous variables.

Most studies on pricing in supply chains involve channel power, which Ansary and Stern originally defined from the perspective of channel members as the control and influence of one channel member over other channel members in the same channel ${ }^{[7]}$. Due to the different strengths and resources of the various channel members in the supply chain, it is common for one member to dominate and take precedence in decision making, so the different dominance scenarios set out in this paper include dual-channel retailer dominance and single-channel e-tailer dominance, and a third scenario where the two are balanced. The superscripts " $D S$," "SS," and " $B T$ " are used to represent the optimal decisions under the three types of dominance: dual channel retailer dominance, single channel e-tailer dominance, and a balance of power between the two, respectively.

Drawing on the linear demand function form constructed by several researchers ${ }^{[8,9]}$, where the physical channel demand and online channel demand for dual-channel retailers as well as the online channel demand for single-channel e-tailers are shown below:

$$
\left\{\begin{array}{c}
D_{r}=(1-\alpha-\beta) Q-p_{r}+k p_{e}+k p_{d} \\
D_{e}=\beta Q-p_{e}+k p_{r}+k p_{d} \\
D_{d}=\alpha Q-p_{d}+k p_{r}+k p_{e}
\end{array}\right.
$$


The profit functions for dual-channel retailers and single-channel e-tailers are expressed as following:

$$
\begin{aligned}
& \pi_{D}=\left(p_{r}-w\right) D_{r}+\left(p_{e}-w\right) D_{e}= \\
& \left(p_{r}-w\right)\left[(1-a-b) Q-p_{r}+k p_{e}+k p_{d}\right]+\left(p_{e}-w\right)\left(b Q-p_{e}+k p_{r}+k p_{d}\right) \\
& \pi_{S}=\left(p_{d}-w\right) D_{d}=\left(p_{d}-w\right)\left(a Q-p_{d}+k p_{r}+k p_{e}\right)
\end{aligned}
$$

\section{Model construction and solving}

In this section, three main types of dominant rights structures are constructed, and the specific optimal solution results are shown in Table 1.

(1) Model $\boldsymbol{D S}$ (Stackelberg game dominated by dual-channel retailers)

It is assumed that both retailers cannot determine their own channel prices and influence the price setting process of the other. In this game, the dual-channel retailer is the leader and the single-channel e-tailer is the follower. Using backward projection, the game model is solved in the following way:

$$
\begin{aligned}
& \max _{p_{r}, p_{e}} \pi_{D}=\left(p_{r}-w\right)\left[(1-\alpha-\beta) Q-p_{r}+k p_{e}+k p_{d}\right]+\left(p_{e}-w\right)\left(\beta Q-p_{e}+k p_{r}+k p_{d}\right) \\
& \text { s.t. } p_{d} \in \arg \max \pi_{S}=\left(p_{d}-w\right)\left(\alpha Q-p_{d}+k p_{r}+k p_{e}\right)
\end{aligned}
$$

(2) Model $\boldsymbol{B T}$ (Bertrand game of equal rights for two retailers)

In this game, the dual-channel retailer and the single-channel e-tailer are in equilibrium and neither of them are able to control the other with their own power. At this point, retailer $\mathrm{S}$ no longer follows retailer D's decision, and each makes its own profit-maximizing price decision, assuming both retailers act simultaneously. The sequence of the game is as follows: retailer D draws up its own physical channel price $P_{r}$ and network channel price $P_{e}$, retailer $\mathrm{S}$ based on its own profit maximization decision network direct channel price $P_{d}$, the objective function of the two sides to find the optimal decision price. The game model is as follows:

$$
\left\{\begin{array}{c}
\max _{p_{r}, p_{e}} \pi_{D}=\left(p_{r}-w\right)\left[(1-\alpha-\beta) Q-p_{r}+k p_{e}+k p_{d}\right]+\left(p_{e}-w\right)\left(\beta Q-p_{e}+k p_{r}+k p_{d}\right) \\
\max _{p_{d}} \pi_{S}=\left(p_{d}-w\right)\left(\alpha Q-p_{d}+k p_{r}+k p_{e}\right)
\end{array}\right.
$$

(3) Model SS (Stackelberg game dominated by single-channel e-retailers)

In this game, the single-channel online retailer is the leader, and the dual-channel retailer is the follower, each considering their own interests to maximize their decisions. Using the backward projection method, the game model is solved in the following way:

$$
\begin{aligned}
& \max _{p_{d}} \pi_{S}=\left(p_{d}-w\right)\left(\alpha Q-p_{d}+k p_{r}+k p_{e}\right) \\
& \text { s.t. } p_{r}, p_{e} \in \arg \max \pi_{D}=\left(p_{r}-w\right)\left[(1-\alpha-\beta) Q-p_{r}+k p_{e}+k p_{d}\right]+\left(p_{e}-w\right)\left(\beta Q-p_{e}+k p_{r}+k p_{d}\right)
\end{aligned}
$$

\section{Comparison under different rights structures}

Proposition 1: Comparing the profits of dual-channel retailers under three types of channel rights structures, i.e., $\pi_{D}{ }^{S S}>\pi_{D}{ }^{D S} \geq \pi_{D}{ }^{B T}$.

Proposition 1 shows that the single-channel e-tailer dominates the highest profit for the dual-channel retailer, and the channel power structure is preferred in the order of $S S \succ D S \succ B T$ from the perspective of maximizing their own interests. 
Proposition 2: Comparing the profits of single-channel e-tailers under three types of channel rights structures, i.e., $\pi_{s}^{D S}>\pi_{s}^{S S} \geq \pi_{s}^{B T}$.

Proposition 2 shows that for a single-channel e-tailer, the profit obtained under the dominant dualchannel retailer is the highest, and therefore, the channel power structure preference order for the singlechannel e-tailer is $D S \succ S S \succ B T$. Combining Proposition 1 and Proposition 2, for both retailers, if they want to maximize their profits, they should give each other priority; that is, they should be under the rights structure that is dominated by the other.

Proposition 3: Under the three types of channel rights structures, there exists a critical value $\alpha_{0}$ for the profit of dual-channel retailers $\pi_{D}$ compared to the profit of single-channel e-tailers $\pi_{S}$. When $\alpha \in\left(0, \alpha_{0}\right)$, then $\pi_{D}>\pi_{S}$; when $\alpha \in\left(\alpha_{0}, 1\right)$, then $\pi_{S}>\pi_{D}$.

Proposition 3 shows that regardless of the channel rights structure, since dual-channel retailers have two distribution channels, online and offline, and a higher market share than single-channel e-tailers, the profits of dual-channel retailers in the first stage are higher than the profits of single-channel e-tailers. As customers have increasing preference for electronic channels of single-channel e-tailers, it brings about a continuous increase in the market share of single-channel e-tailers. Therefore, the profit of single-channel e-tailers in the second stage would in turn exceed that of dual-channel retailers, i.e., $\pi_{S}>\pi_{D}$.

Table 1. Optimal solution under different dominant rights

\begin{tabular}{cccc}
\hline & $\boldsymbol{D S}$ & $\boldsymbol{B T}$ & $\boldsymbol{S S}$ \\
\hline$p_{r}$ & $\frac{B_{1} w+Q\left[(1-2 \alpha-2 \beta) k^{2}-(\alpha+2 \beta) k-2(1-\alpha-\beta)\right]}{4\left(k^{3}+2 k^{2}-1\right)}$ & $\frac{H_{1} Q+2\left(k^{2}-k-2\right) w}{4\left(k^{3}+3 k^{2}-2\right)}$ & $\frac{H_{5} Q-2\left(3 k^{2}+k-2\right) w}{8\left(k^{4}+k^{3}-2 k^{2}-k+1\right)}$ \\
$p_{e}$ & $\frac{B_{1} w-Q\left[(1-2 \beta) k^{2}+(2-\alpha-2 \beta) k+2 \beta\right]}{4\left(k^{3}+2 k^{2}-1\right)}$ & $\frac{H_{2} Q+2\left(k^{2}-k-2\right) w}{4\left(k^{3}+3 k^{2}-2\right)}$ & $\frac{H_{6} Q-2\left(3 k^{2}+k-2\right) w}{8\left(k^{4}+k^{3}-2 k^{2}-k+1\right)}$ \\
$p_{d}$ & $\frac{\left(2 k^{3}+3 k^{2}-2\right) w+\left(\alpha k^{2}+3 \alpha k-k-2 \alpha\right) Q}{4\left(k^{2}+k-1\right)}$ & $\frac{(3 \alpha k-k-2 \alpha) Q-2\left(1-k^{2}\right) w}{2\left(k^{2}+2 k-2\right)}$ & $\frac{(3 \alpha k-k-2 \alpha) Q+2\left(2 k^{2}-1\right) w}{4\left(k^{2}+k-1\right)}$ \\
$D_{r}$ & $\frac{\left(2 k^{2}+3 k-2\right) w+[\alpha k+2(1-\alpha-\beta)] Q}{4}$ & $\frac{H_{3} Q+2\left(2 k^{3}+k^{2}-5 k+2\right) w}{4\left(k^{2}+2 k-2\right)}$ & $\frac{C_{4} Q+2\left(4 k^{3}-5 k+2\right) w}{8\left(k^{2}+k-1\right)}$ \\
$D_{e}$ & $\frac{\left(2 k^{2}+3 k-2\right) w+(\alpha k+2 \beta) Q}{4}$ & $\frac{H_{4} Q+2\left(2 k^{3}+k^{2}-5 k+2\right) w}{4\left(k^{2}+2 k-2\right)}$ & $\frac{C_{5} Q+2\left(4 k^{3}-5 k+2\right) w}{8\left(k^{2}+k-1\right)}$ \\
$D_{d}$ & $\frac{\left(2 k^{3}-k^{2}-4 k+2\right) w+\left(\alpha k^{2}+3 \alpha k-k-2 \alpha\right) Q}{4\left(k^{2}+k-1\right)}$ & $\frac{(3 \alpha k-k-2 \alpha) Q+2(1-2 k) w}{2\left(k^{2}+2 k-2\right)}$ & $\frac{(2 \alpha+k-3 \alpha k) Q-2(1-2 k) w}{4(1-k)}$ \\
$\pi_{D}$ & $\frac{B_{2} Q^{2}+2 B_{3} w Q+B_{4} w^{2}}{8\left(1-k^{3}-2 k^{2}\right)}$ & $\frac{C_{1} Q^{2}+8 C_{2} w Q+4 C_{3} w^{2}}{8(k+1)\left(k^{2}+2 k-2\right)^{2}}$ & $\frac{S_{1} Q^{2}-S_{2} w Q-4 S_{3} w^{2}}{32\left(k^{2}-1\right)\left(k^{2}+k-1\right)^{2}}$ \\
$\pi_{S}$ & $\frac{\left[\left(2 k^{3}-k^{2}-4 k+2\right) w+\left(\alpha k^{2}+3 \alpha k-k-2 \alpha\right) Q\right]^{2}}{\left[4\left(k^{2}+k-1\right)\right]^{2}}$ & $\frac{[(3 \alpha k-k-2 \alpha) Q+2(1-2 k) w]^{2}}{\left[2\left(k^{2}+2 k-2\right)\right]^{2}}$ & $\frac{[(2 \alpha+k-3 \alpha k) Q-2(1-2 k) w]^{2}}{16\left(k^{3}-2 k+1\right)}$ \\
\hline
\end{tabular}

Note: The coefficients in the table are shown in the Appendix.

Proposition 4: Analyzing the changes in the physical channel for dual-channel retailers under three types of channel rights structures, $p_{r}^{D S}, p_{r}^{B T}, p_{r}^{S S}, D_{r}^{D S}, D_{r}^{B T}$, and $D_{r}^{S S}$ decrease with increasing coefficients $\alpha$ and $\beta$.

Proposition 4 suggests that as customers' acceptance toward e-channel products grows, both the increase in customer preference for dual-channel retailers' e-channel $\alpha$ and single-channel e-tailers' echannel $\beta$ would directly impact product sales in the physical channel, forcing merchants to lower the prices in their physical channels.

Proposition 5: Analyzing the changes in the network channel of dual-channel retailers under three types of channel rights structures, $p_{e}{ }^{D S}, p_{e}{ }^{B T}$, and $p_{e}^{S S}$ increase with increasing coefficient $\beta$ but decrease with increasing coefficient $\alpha, D_{e}^{D S}, D_{e}^{B T}$, and $D_{e}^{S S}$ increase with increasing coefficients $\alpha$ 
and $\beta$.

Proposition 5 suggests that regardless of the channel power structure, an increase in customer preference for an online channel owned by a dual-channel retailer would lead to an increase in market demand for that channel, and correspondingly, an increase in online channel prices. When customers have increasing preference for an online channel run by a single-channel e-tailer, it does not significantly impact the dual-channel retailer's online channel demand, but rather increases it. However, in order to compete for online market shares, the dual-channel retailer would then lower the prices to attract customers.

\section{Conclusion and management insights}

This study considers the design of a multi-channel supply chain with elastic competition coefficients between physical and online channels as well as the degree of customer channel preference. It explores the issue of optimal selection strategies under different channel rights structures. Three main conclusions have been drawn from this study.

(1) The online channel prices of both retailers increase as their respective customer channel preferences increase, impacting the business conditions of brick-and-mortar stores regardless of whether customers gradually prefer online channels run by dual-channel retailers or those run by singlechannel e-tailers. In addition, the gradual preference of customers for online channels run by singlechannel e-tailers does not lead to a decrease in demand for online channels run by dual-channel retailers, but rather a small increase. In addition to that, dual-channel retailers would usually reduce their own e-prices for the online channels as deemed appropriate to attract more customers.

(2) The profits of both dual-channel retailers and single-channel e-tailers are lowest under the Bertrand game, suggesting that when there are two retailers with balanced power, the effect of unhealthy competition would be the least profitable for both parties.

\section{Appendix}

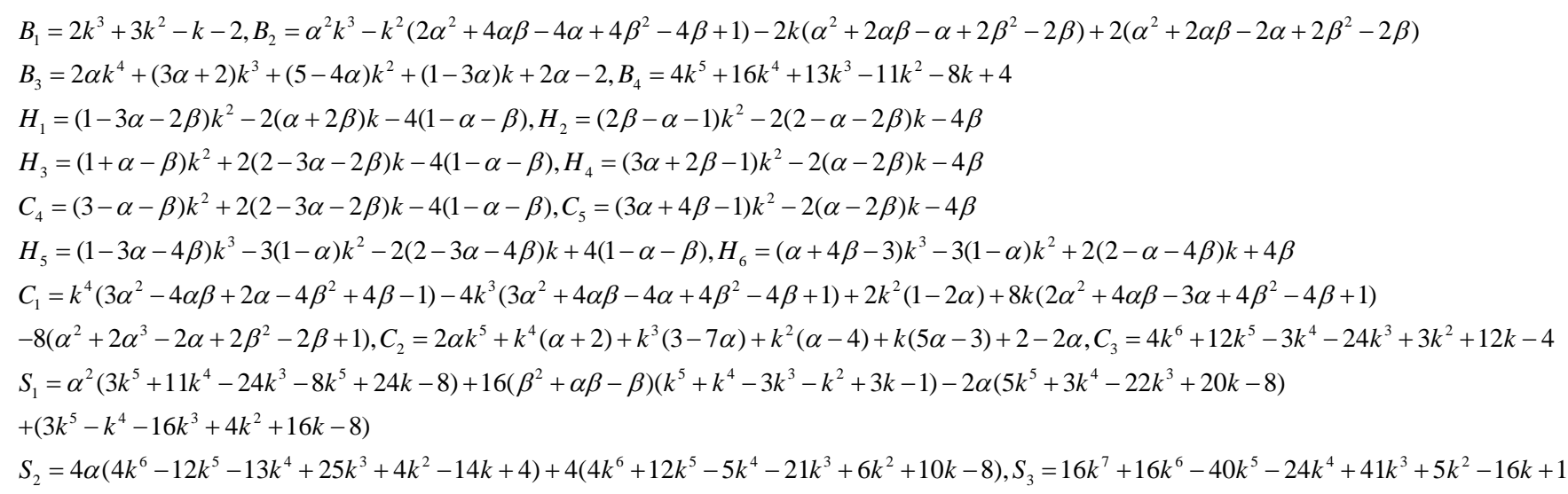

\section{Disclosure statement}

The author declares that there is no conflict of interest.

\section{References}

[1] Xu G, Dan B, Zhang X, 2014, Coordinating a Dual-Channel Supply Chain with Risk-Averse under a Two-Way Revenue Sharing Contract. Int J Prod Econ, 147(A): 171-179. 
[2] Cai G, 2010, Channel Selection and Coordination in Dual-Channel Supply Chains. J Retailing, 86(1): 22-36.

[3] Xu Q, Fu G, Fan D, 2020, Service Sharing, Profit Mode and Coordination Mechanism in the Onlineto-Offline Retail Market. Econ Model, 91: 659-669.

[4] He P, He Y, Xu H, 2019, Channel Structure and Pricing in a Dual-Channel Closed-Loop Supply Chain with Government Subsidy. Int J Prod Econ, 213: 108-123.

[5] He Y, Huang H, Li D, 2020, Inventory and Pricing Decisions for a Dual-Channel Supply Chain with Deteriorating Products. Oper Res, 20(3): 1461-1503.

[6] Lin X, Zhou Y, Xie W, 2020, Pricing and Product-bundling Strategies for E-commerce Platforms with Competition. Eur J Oper Res, 283(3): 1026-1039.

[7] Ansary AE, Stern LW, 1972, Power Measurement in the Distribution Channel. J Market Res, 9: 1118.

[8] Wang W, Li G, Cheng T, 2016, Channel Selection in a Supply Chain with a Multi-Channel Retailer: The Role of Channel Operating Costs. Int J Prod Econ, 173: 54-65.

[9] Zhang P, He Y, Shi C, 2017, Retailer's Channel Structure Choice: Online Channel, Offline Channel, or Dual Channels? Int J Prod Econ, 191: 37-50. 